TECHNICAL PAPER

\title{
BROADCAST DISTRIBUTION UNIFORMITY OF FERTILIZER WITH CENTRIFUGAL SPREADERS USED IN VARIABLE RATE APPLICATION
}

Doi:http://dx.doi.org/10.1590/1809-4430-Eng.Agric.v36n5p928-937/2016

\section{JOÃO P. A. R. CUNHA ${ }^{1 *}$, ROMEU SOARES FILHO ${ }^{2}$}

\begin{abstract}
The quality of fertilizer distribution process is important to the success of agriculture. This research aimed to study the distribution uniformity of fertilizers with spreaders capable of performing variable rate. Evaluations were carried out in different farms, in the Southwest region of the State of Goiás, Brazil. 13 longitudinal and transversal distribution profiles with 11 centrifugal spreaders were evaluated: five with limestone, two with gypsum, two with magnesium oxide, one with monoammonium phosphate (MAP), one with super simple phosphate (SS), one with chloride potassium $(\mathrm{KCl})$ and one with formulated fertilizer (02-20-20). The collectors and the form of distribution followed the ASABE S341.3 standard (2006). The broadcasted distribution by centrifugal spreaders performed unevenly over the applied area. Therefore, application evaluation, in addition to correct regulation, should be performed frequently for each type of product, even on machines with capacity in variable rate.
\end{abstract}

KEY WORDS: fertilizer distribution, broadcast spreaders, precision agriculture.

\section{INTRODUCTION}

The distribution of soil correctives and fertilizes, in annual crops, through centrifugal spreaders is the most used method in field due to high operating capacity and wide range of doses (LAGHARI et al., 2014).However, it can have low distribution uniformity with high coefficients of variation (SERRANO et al., 2007; BAIO et al., 2012; BRAMLEY \& TRENGOVE, 2013).

The distribution mechanism by centrifugal force is characterized by using one or two rotors (discs) with horizontal fins to the radial distribution of the product, being very important for proper disposal at ground (YILDIRIM \& KARA, 2012). The particle size of the fertilizer is also a parameter that affects the distribution in this type of machines, and the denser particles are thrown to greater distances (GOSS et al., 2010). Equally, wind speed and moisture affect the product distribution uniformity.

We have in this context the precision agriculture. Many agricultural machinery companies have sold the adaptation of fertilizers application systems to variable rate in centrifugal distributors, but this incorporation of technology will not help if the distribution uniformity of the equipment is not adequate.

Thus, this study aimed to diagnose the uniformity of broadcast distribution of fertilizers in machines capable of performing variable rate, in a grain production region.

\section{SUBJECT DESCRIPTION}

The evaluations were carried out in farms located in the Southwest region of the State of Goiás, Brazil, in the cities of Rio Verde, Jataí, Mineiros and Montividiu. The sample used in the diagnosis was made by non-probabilistic method. The use of non-probabilistic method was due to the fact that the population was not available to be randomly selected and the selection of the sample elements depended on the investigator's judgment. The initial stage of the research was the identification of producers that used variable rate application. This identification was made through

\footnotetext{
${ }^{1}$ Universidade Federal de Uberlândia/Uberlândia-MG, Brasil

${ }^{2}$ EMATER-GO/Rio Verde, Brasil.

*Corresponding author. E-mail: jpcunha@ufu.br

Received in: 1-7-2016

Accepted in: 5-23-2016
} 
contacts with technical assistance, rural extension companies, cooperatives and indications of the interviewed producers.

Given that, the application of fertilizers in the region is mainly made with broadcast distribution, so we promoted the quality evaluation of these distributions. Producers who were willing to have the quality of the products distribution analyzed were selected. The evaluations were made on the farm during a normal application, under field conditions, from the modified methodology of MILAN \& GARDANHA JUNIOR (1996) and LUZ et al. (2010). We evaluated the transverse and longitudinal profiles of the machines distribution by keeping the regulation in the conditions performed by the producer.

Thirteen evaluations were made: five with limestone, two with gypsum, two with magnesium oxide, one with monoammonium phosphate (MAP), one with super simple phosphate (SS), one with chloride potassium (KCl) and one with formulated fertilizer (02-20-20). The evaluations with magnesium oxide were made with the same machine, the same happened with an evaluation of gypsum and limestone that also used the same equipment.

The collectors used and the form of distribution followed the ASABE S341.3 standard (ASABE, 2006).For the evaluation, collectors of $1.0 \times 0.25 \mathrm{~m}$ were used, being 50 distributed in pairs along the center of distribution of the products, spaced in $1.0 \mathrm{~m}$, totaling $49 \mathrm{~m}$ in length, in a way to collect the products distributed in the central range of distribution.

We also placed 50 collectors distributed across the machine movement. For the powder fertilizers, the collectors were placed every $0.25 \mathrm{~m}$, with the exception of the two central collectors that were put together, leaving $2.50 \mathrm{~m}$ for the passage of the equipment rotated, $1.25 \mathrm{~m}$ on each side, totaling $26.5 \mathrm{~m}$. In the case of granular fertilizers, collectors were placed every $0.50 \mathrm{~m}$, with the exception of the two central collectors that were put together, leaving $2.50 \mathrm{~m}$ for the passage of the equipment rotated, $1.25 \mathrm{~m}$ on each side, totaling $38 \mathrm{~m}$.

To prevent the ricochet of the particles, shading mesh with $30 \%$ of shading was placed inside the collectors. The tests were carried out in a flat site (up to $2 \%$ of slope) and without vegetation interference.

The working speed during the evaluations varied according to the equipment used: $1.39 \mathrm{~m} \mathrm{~s}^{-1}$, in the case of drag distributors, up to $5.14 \mathrm{~m} \mathrm{~s}^{-1}$, when the self-propelled equipment was used (Table 1).At least a $10 \mathrm{~m}$ path before the collector was used to stabilize the linear velocity and the angular speed of the power take-off (PTO). The working height was in accordance with the recommendation of the equipment manufacturer and the dose of fertilizers and correctives to be applied were obtained from the adjustment by the operator, before the implementation, using the methodology and tables recommended by the manufacturer. The distribution range also varied depending on the distributed product and on the equipment used, always paying attention to the settings used for each property, which means that we adopted the working width informed by the operator. The dosages used in the tests were set for the plot in question in order to permit the evaluation of the distribution uniformity. We used the dose indicated by each operator as the one that the machine was set. 
TABLE 1. Speed, distribution range and doses used during the evaluation of the product distribution quality.

\begin{tabular}{ccccc}
\hline Product & Distributor* & $\begin{array}{c}\text { Application } \\
\text { speed } \\
\left(\mathrm{m} \mathrm{s}^{-1}\right)\end{array}$ & $\begin{array}{c}\text { Distribution } \\
\text { range adopted by } \\
\text { the operator }(\mathrm{m})\end{array}$ & $\begin{array}{c}\text { Dose } \\
\left(\mathrm{kg} \mathrm{ha}^{-1}\right)\end{array}$ \\
\hline $\begin{array}{c}\text { Potassium Chloride (KCl) } \\
\text { Monoammonium phosphate (MAP) }\end{array}$ & 2 & 5.00 & 30 & 180 \\
Simple superphosphate (SS) & 4 & 5.14 & 30 & 250 \\
02-20-20 & 1 & 5.00 & 30 & 280 \\
Limestone 1 & 3 & 1.67 & 30 & 300 \\
Limestone 2 & 5 & 1.39 & 8 & 2.000 \\
Limestone 3 & 6 & 2.56 & 11 & 2.000 \\
Limestone 4 & 4 & 2.69 & 8 & 2.000 \\
Limestone 5 & 1 & 1.67 & 14 & 2.000 \\
Gypsum 1 & 1 & 5.00 & 9 & 2.000 \\
Gypsum 2 & 4 & 2.69 & 20 & 700 \\
Magnesium oxide 1 & 1 & 2.22 & 18 & 1.000 \\
Magnesium oxide 2 & 1 & 2.22 & 10 & 500 \\
\end{tabular}

${ }^{* 1}$ Stara distributor, Hercules 10.000 model; ${ }^{2}$ Jumil distributor, Precisa 6 m model; ${ }^{3}$ Stara distributor, Hercules 24.000 model; ${ }^{4}$ selfpropelled Stara distributor, Hercules 5.0 model; ${ }^{5}$ Jan distributor, Lancer Maximus 25.000 model; and ${ }^{6}$ Jan distributor, Lancer Maximus 12.000 model.

After application, the material of each collector was collected, packed in plastic bags, identified and weighted on AS 500 precision scale (Marte, São Paulo), with a resolution of $0.01 \mathrm{~g}$. Subsequently, we carried out the particle size analysis and determined moisture and density to characterize the materials used.

In the evaluations of the transverse and longitudinal distributions, eleven centrifugal distributors with capacity for distribution in variable rate were used, even though they were set to constant rate during the test: four Stara distributors, Hercules 10.000 model; two Jumil distributors, Precisa $6 \mathrm{~m}$ model; one Stara distributor, Hercules 24.000 model; two self-propelled Stara distributor, Hercules 5.0 model; one Jan distributor, Lancer Maximus 25.000 model; and one Jan distributor, Lancer Maximus 12.000 model. These machines are equipped with conveyor belt and distribution mechanism of the two horizontal rotors with fins type.

The wind speed, temperature and relative humidity during the tests were determined using a hygro thermo anemometer light meter.

From the weighing of the collected product, the analysis of data for the verification among the desired dose, the applied dose and the deposition range characteristics were carried out. The overlap was simulated using the Adulanço 3.0 computer program (MOLIN, 2009). The coefficient of variation of the transversal position was obtained from the working width used, considering the alternating displacement to the right or to the left, as the operation was performed in field.

\section{Weather conditions and soil correctives and fertilizer moisture}

Air relative humidity above $80 \%$ and wind speed above $2 \mathrm{~m} \mathrm{~s}^{-1}$ are inadequate factors when the distribution is broadcast because they affect the trajectory of the particles (PORTELA \& BATISTA, 2012). It is verified in Table 2, the four fertilizers, except for the $\mathrm{KCl}$, the wind speed was inadequate for good distribution uniformity. In relation to the products moisture, all showed values under $6 \%$, considered low. 
TABLE 2. Fertilizer moisture, wind speed, air relative humidity and temperature at the time of the broadcast distribution of the four granular fertilizers.

\begin{tabular}{ccccc}
\hline Product & $\begin{array}{c}\text { Wind speed } \\
\left(\mathrm{m} \mathrm{s}^{-1}\right)\end{array}$ & $\begin{array}{c}\text { Relative Humidity } \\
(\%)\end{array}$ & $\begin{array}{c}\text { Temperature } \\
\left({ }^{\circ} \mathrm{C}\right)\end{array}$ & Product moisture (\%) \\
\hline KCl & 0.94 & 32.7 & 31.1 & 0.15 \\
MAP & 3.22 & 72.8 & 22.3 & 5.89 \\
SS & 2.33 & 25.7 & 35.8 & 3.24 \\
$02-20-20$ & 4.50 & 21.4 & 43.2 & 5.26 \\
\hline
\end{tabular}

In relation to the weather conditions by the time of the evaluations with powder fertilizers (Table 3), we note that the wind speed, most responsible for drift, also had unsuitable levels for distribution, according to the ASABE S341.3 standard (ASABE, 2006), which defines that the wind speed in the application is less than $2.22 \mathrm{~m} \mathrm{~s}^{-1}$, with the slope of the ground up to $2 \%$. Although they are not appropriate, yet the producers were applying fertilizers in the area due to shortage of time, and because of that we carried out the evaluation to make the diagnosis, which sought to characterize the real situation in the field.

TABLE 3. Fertilizer moisture, wind speed, air relative humidity and temperature at the time of the broadcast distribution of the powder fertilizers.

\begin{tabular}{ccccc}
\hline Product & $\begin{array}{c}\text { Wind speed } \\
\left(\mathrm{m} \mathrm{s}^{-1}\right)\end{array}$ & Air relative humidity & $\begin{array}{c}\text { Temperature } \\
\left({ }^{\circ} \mathrm{C}\right)\end{array}$ & Product moisture $(\%)$ \\
\hline Limestone 1 & 3.31 & 24.9 & 60.8 & 6.41 \\
Limestone 2 & 3.00 & 36.7 & 21.4 & 7.21 \\
Limestone 3 & 2.78 & 32.9 & 21.7 & 3.34 \\
Limestone 4 & 3.19 & 35.2 & 25.0 & 2.33 \\
Limestone 5 & 1.89 & 34.8 & 27.2 & 3.49 \\
Gypsum 1 & 1.61 & 32.7 & 24.4 & 38.77 \\
Gypsum 2 & 1.83 & 28.8 & 52.1 & 18.32 \\
MgO 1 & 1.72 & 33.6 & 29.4 & 0.36 \\
MgO 2 & 0.97 & 39.5 & 21.4 & 0.48 \\
\hline
\end{tabular}

Regarding the moisture of powder fertilizers, limestone showed values lower than $7.21 \%$. In the case of gypsum, as it comes from the factory with high moisture content, in its distribution there is the formation of clods or lumps that on the one hand avoids to be blown away by the wind, on the other causes the uneven deposition, since the distribution of these lumps make the concentration of gypsum on the soil surface in randomly distributed places.

In relation to the magnesium oxide, product obtained by the calcination of the Magnesite, the product was dry by the distribution time, highly susceptible to be blown away by the wind.

\section{Particle size of soil correctives and fertilizers}

The uniformity of broadcast distribution is affected by the grain size of the applied products. Since the distribution distance of the granule in the broadcast distribution depends on the mass, we hope that materials with larger granules reach longer distances in the distribution. According to Table 4, the superphosphate had smaller size particles between the granules, as KCl, MAP and 0220-20 mostly had particles between 2 and $4 \mathrm{~mm}$. 
TABLE 4. Percentage of size fractions of granular products used in broadcast distribution.

\begin{tabular}{ccccc}
\hline \multirow{2}{*}{ Product } & \multicolumn{4}{c}{ Particle size $(\%)$} \\
\cline { 2 - 5 } & $>4 \mathrm{~mm}$ & $4-2 \mathrm{~mm}$ & $2-1 \mathrm{~mm}$ & $<1 \mathrm{~mm}$ \\
\hline KCl & 1.17 & 88.16 & 9.67 & 1.00 \\
MAP & 0.86 & 89.28 & 9.27 & 0.60 \\
SS & 0.00 & 9.06 & 85.94 & 4.99 \\
$02-20-20$ & 5.14 & 83.26 & 0.86 & 10.74 \\
\hline
\end{tabular}

We observed in Table 5 that for the same product there are differences in physical characteristics that affect the broadcast distribution by centrifugal force. In the case of limestone, we know that larger particles are heavier and are distributed farther away from the centrifugal force and are less susceptible to be blown away by the wind.

TABLE 5. Percentage of size fractions of powder products used in broadcast distribution.

\begin{tabular}{ccccccc}
\hline Product & $4.0 \mathrm{~mm}$ & $2.0 \mathrm{~mm}$ & $1.0 \mathrm{~mm}$ & $0.85 \mathrm{~mm}$ & $0.425 \mathrm{~mm}$ & Bottom \\
\hline Limestone 1 & 1.25 & 1.41 & 8.99 & 2.92 & 48.44 & 36.99 \\
Limestone 2 & 2.31 & 1.48 & 86.48 & 0.72 & 5.43 & 3.58 \\
Limestone 3 & 3.88 & 1.47 & 4.81 & 2.24 & 19.83 & 67.77 \\
Limestone 4 & 0.95 & 0.80 & 1.91 & 1.23 & 19.94 & 75.17 \\
Limestone 5 & 0.19 & 0.38 & 3.15 & 2.36 & 1.51 & 74.41 \\
Gypsum 1 & 20.31 & 53.13 & 25.00 & 0.17 & 1.03 & 0.17 \\
Gypsum 2 & 23.72 & 54.87 & 19.92 & 0.35 & 0.93 & 0.21 \\
MgO 1 & 0.00 & 0.00 & 1.83 & 1.63 & 57.18 & 39.30 \\
MgO 2 & 0.00 & 0.00 & 0.00 & 0.03 & 7.38 & 92.59 \\
\hline
\end{tabular}

\section{Transverse distribution of granular fertilizer}

There was a trend of lower deposition in the central range of the distribution of granular fertilizers, which can hardly be compensated by overlapping passes (Figure 1).In the case of 02-2020 fertilizer, we notice the wind influence of $4.5 \mathrm{~m} \mathrm{~s}^{-1}$ in the transverse direction to the displacement, distributing the granules at distances over $19 \mathrm{~m}$.
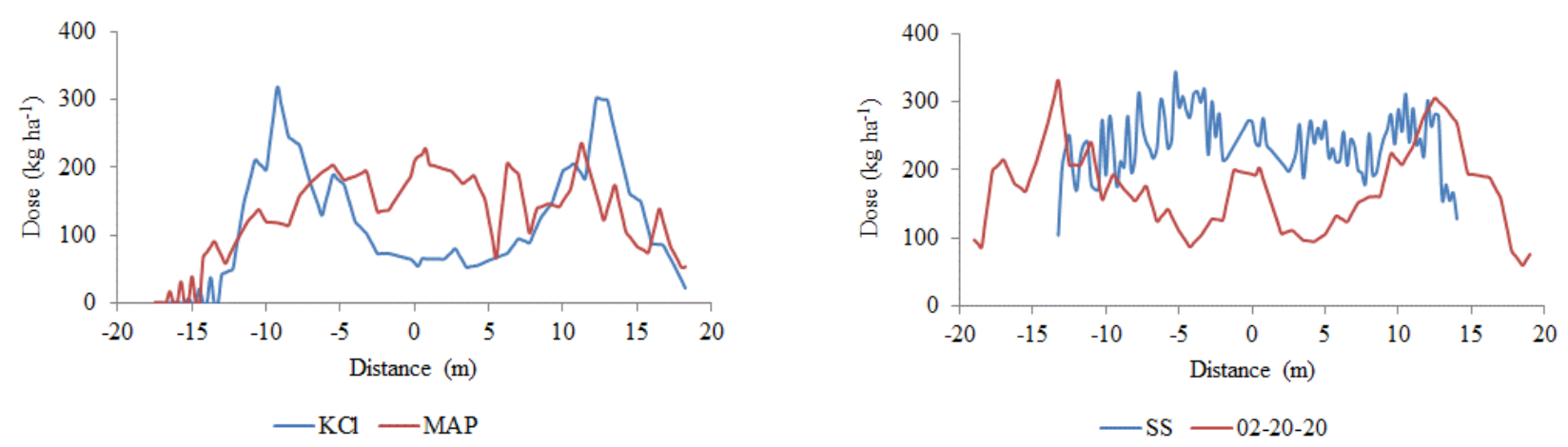

FIGURE 1. Transverse distribution patterns of $\mathrm{KCl}$ at $180 \mathrm{~kg} \mathrm{ha}^{-1}, \mathrm{MAP}$ at $250 \mathrm{~kg} \mathrm{ha}^{-1}$, SS at 280 $\mathrm{kg} \mathrm{ha}^{-1}$, and 02-20-20 at $300 \mathrm{~kg} \mathrm{ha}^{-1}$, using broadcast spreader.

As the applied doses of each product were different, it is important to analyze the profile of the curve and not the point values. The broadcast distribution may be influenced by characteristics of the equipment, such as the rotation of the discs and the position of the fins, as by external factors to the distributor assembly, such as climatic conditions, vegetation on soil, land slope and especially the features of the used product (MOLIN et al., 2010).In the case of granular products, the wind effect is less due to the granules mass. 
Comparing the profile obtained for the 02-20-20 formulated fertilizer with the obtained profiles by MOLIN et al (2009) also working with formulated fertilizer in centrifugal distributors, we can see many similarities. The authors showed the occurrence of the profile in a "W" shape, with peaks of larger amount of fertilizer applied at the sides and rising in the center.

\section{Transverse distribution of limestone}

We note that if the transverse distribution of limestone was not symmetrical, it always tend to shift to one of the lateral (Figure 2).This can also be explained by the occurrence of wind, which means that the finer lime is blown out of the application range. In the case of limestone 2, the granules were distributed at greatest distance due to the larger size.

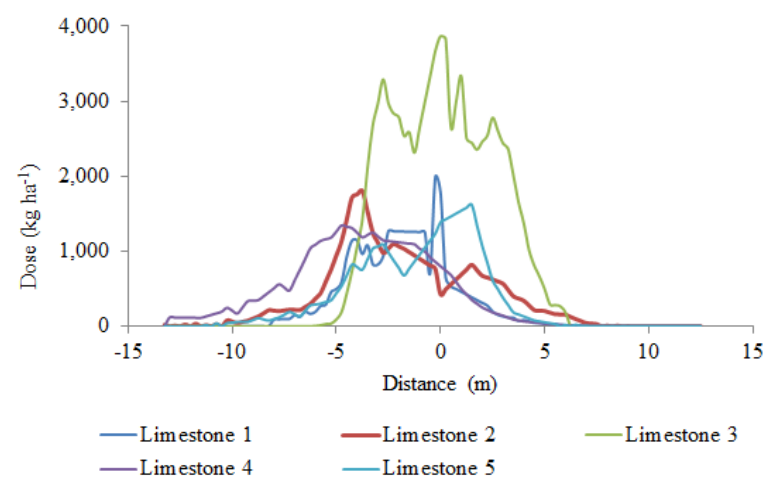

FIGURE 2. Transverse distribution of five limestones, using broadcast spreader.

The distribution of limestone 4 showed more symmetrical profile, which is the product, between the different limestones, with less moisture. LUZ et al. (2010), evaluating the transverse distribution of the limestone with $1.8 \%$ moisture also found a symmetrical profile with the use of a centrifugal distributor of double disc.

\section{Transverse distribution of gypsum}

The transverse distribution of gypsum showed an irregular manner (Figure 3). The gypsum, even with very fine grain when dry, usually comes from industry with high moisture and so it is applied. The wet gypsum tends to form clumps, manifesting as if it had larger granules.

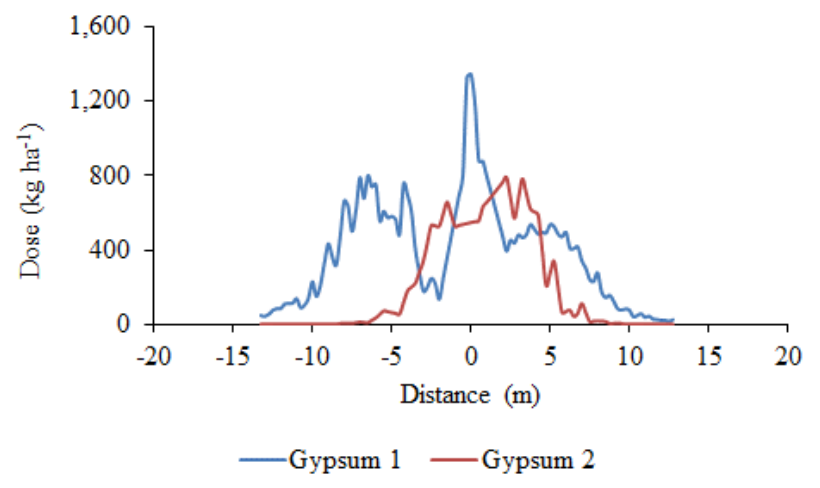

FIGURE 3. Transverse distribution of patterns of two gypsum samples, using broadcast spreader.

We note that there was a greater heterogeneity in the distribution of gypsum 1with failures in the center of the deposition. From Table 3, it is clear that in this case the moisture of the product was about $38 \%$ when compared to $18 \%$ for gypsum 2 . Higher moisture results in formation of lumps that are distributed, by centrifugal force, out of the distribution center range. This finding corroborates with the results of LUZ et al. (2010), who found suitable transverse profile for the distribution of gypsum with $15 \%$ humidity. The authors state that moisture hampers the flowability of the product in the spreader mechanism of the equipment. 


\section{Transverse distribution of magnesium oxide}

The transverse distribution of the magnesium oxide broadcasted behaved, similarly to limestone, very uneven, as shown in Figure 4.The wind effect in the case of magnesium oxide 2 was more evidenced because the product was very fine grain size and dried enough. Even the wind velocity being $0.97 \mathrm{~m} \mathrm{~s}^{-1}$ caused the product to be blown into the right lateral band. Magnesium oxide 1 had a rectangular profile, which depending on the working width, can lead to low distribution uniformity.

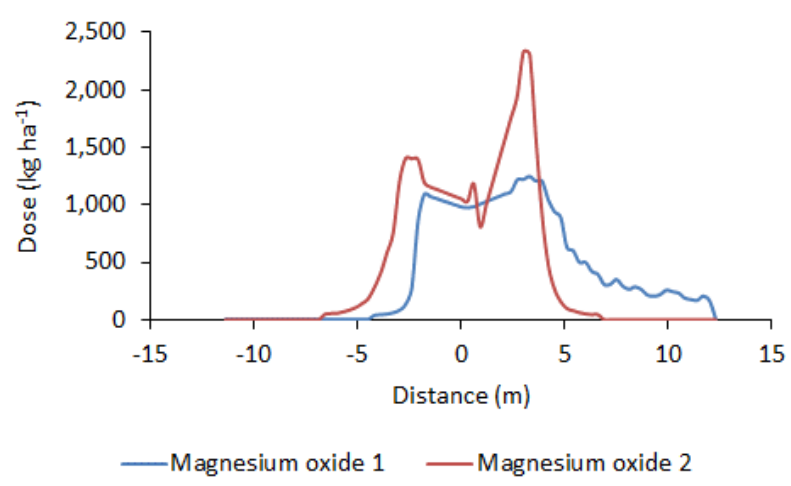

FIGURE 4. Transverse distribution patterns of two magnesium oxide samples, using broadcast spreader.

\section{Coefficient of variation in transverse distribution}

The coefficient of variation measures the deposition uniformity of fertilizer in the transverse distribution. The amount variation around the average allows measuring the distribution quality. According to CROZIER \& ROBERSON (2014), coefficient up to $20 \%$ is considered satisfactory.

According to Table 6, there was substantial heterogeneity among the products. In the case of potassium chloride and 02-20-20 formulated fertilizer, the coefficient of variation was greater than $50 \%$. The deposition on the central band was much smaller in comparison with the ends (Figure 1).Probably; this was due to the particle size of the product, where it has the most part with a diameter greater than $2.00 \mathrm{~mm}$, with enough mass to be distributed to great distances.

TABLE 6. Coefficient of variation of the transverse distribution patterns of fertilizer samples, using broadcast spreader.

\begin{tabular}{cccc}
\hline Product & CV $(\%)$ & Product & CV (\%) \\
\hline Limestone 1 & 17.29 & $\mathrm{MgO} \mathrm{1}$ & 88.28 \\
Limestone 2 & 27.84 & $\mathrm{MgO} \mathrm{2}$ & 15.52 \\
Limestone 3 & 13.89 & $\mathrm{KCl}$ & 51.40 \\
Limestone 4 & 30.31 & $\mathrm{MAP}$ & 21.16 \\
Limestone 5 & 13.53 & $\mathrm{SS}$ & 24.27 \\
Gypsum 1 & 51.11 & $02-20-20$ & 51.57 \\
Gypsum 2 & 16.61 & & \\
\hline
\end{tabular}

For powder products, more subject to have interference from wind conditions, the transverse distribution variation coefficient is generally higher. In the case of the limestone evaluated in diagnosis, for used working widths, the coefficients were higher than the recommended in the literature.

It is noteworthy that the coefficient of variation depends on how the machine displacement is done in the field. The broadcast application can be made with the displacement of the applicator assembly in alternating left, alternating right and continuously opening or closing the plot. When making the displacement alternately in the direction of the prevailing wind it attenuates the effect of 
the product drift in the presence of winds. We verified that the limestone have coefficients of variation between 13.89 and $30.31 \%$.

The coefficient of variation of the transverse distribution of gypsum 1 was higher than $50 \%$, demonstrating the great unevenness in the application under the evaluated conditions. It is not possible to think in application in variable rate, with coefficient of variation of this magnitude. Gypsum 2 showed satisfactory coefficient of variation. This result is possibly linked to the moisture of the two products, which was much higher in gypsum 2, promoting uneven distribution.

In the case of magnesium oxide, the coefficient of variation ranged from $15.25 \%$ for the magnesium oxide 2 to $88.28 \%$ for the magnesium oxide 1 .In the case of magnesium oxide 2 , due to finer grain size, the distribution had wind influence, but with the direction of displacement alternating right, the new distribution compensate the dragging made by the wind on the previous distribution.

It is important to note that the measured coefficients of variation are linked directly to the working width adopted for each condition, which demonstrates the need to adjust the machine for each working condition, as reported by DELAFOSSE \& BOGLIANI (1989).

In this type of test, it is difficult to isolate all the variables, especially in relation to weather conditions. In this sense, it is not always possible to identify the exact cause of a low uniformity. In addition to speed, nature of the product and wind, another factor that can influence the distribution is the surface of the ground. PARISH (1991) showed that irregularities in the ground surface can double the coefficient of variation of transverse distribution.

Anyway, there is a need to carry out a correct adjustment and checking steadily, particularly following the changes in operating conditions. The fact that the machine has a high technological level, making it able to change the dose over the applied area, it does not exempt the distribution evaluation. In addition, the adaptation of systems for variable rate application in centrifugal distributors must be preceded by a detailed analysis in order to verify that the equipment allows a uniform application. Whenever it is possible, the feasibility of using machines with other principles of distribution should be checked, which may allow more uniform distribution.

\section{Coefficient of variation in longitudinal distribution}

In Table 7 can be seen the variation of the longitudinal position of the products on the collector as distributors moved over the soil surface. In this distribution region, the influence of external factors such as wind speed and terrain relief is small, since the distance of displacement of the distributor output product to the ground is reduced. As the overlap occurs on the sides, it is expected that little or no increase in product reaches the center line of distribution. In this case, the amount deposited in this location can be extrapolated for the entire area in question.

TABLE 7. Coefficient of variation of longitudinal distribution patterns of fertilizer samples, using broadcast spreader.

\begin{tabular}{cccc}
\hline Product & CV $(\%)$ & Product & CV $(\%)$ \\
\hline Limestone 1 & 23.71 & KCl & 6.28 \\
Limestone 2 & 24.97 & MAP & 14.61 \\
Limestone 3 & 16.94 & SS & 17.98 \\
Limestone 4 & 24.40 & $02-20-20$ & 19.81 \\
Limestone 5 & 18.56 & & \\
Gypsum 1 & 52.39 & & \\
Gypsum 2 & 17.58 & & \\
\hline
\end{tabular}

In general, the broadcast distribution has higher concentration of products in the center area. In the case of limestone and gypsum that have finer grain size, this effect is even greater because there is less kinetic energy applied to the particles. We noticed a great variability in deposition across the area in the case of gypsum 1, which prevents a good distribution. Possibly, this was due 
to the high moisture of the product (38.77\%), which prevents the continuous flow of the material, which together with the high speed of the machine displacement $\left(5 \mathrm{~m} \mathrm{~s}^{-1}\right)$ promotes the formation of peaks in the distribution.

Depending on the magnitude of the coefficients of variation found, WERNER et al. (2007) recommend that in precision agriculture the applications in variable rate must be made through management zones, since small variability of fertility are unlikely to be corrected using centrifugal distributors, given the very limitation of the equipment.

\section{CONCLUSIONS}

The coefficient of variation of transverse and longitudinal distribution of fertilizers promoted by centrifugal distributor, in the field situation, ranged from $13 \%$ to $88 \%$ and $6 \%$ to $52 \%$, respectively, showing a large variation. Therefore, application tests, in addition to adequate regulation, should be performed frequently for each type of product, even on machines with application capacity in variable rate.

\section{REFERENCES}

ASABE - AMERICAN SOCIETY OF AGRICULTURAL AND BIOLOGICAL ENGINEERS. ASABE S341.3. Procedure for measuring distribution uniformity and calibrating granular broadcast spreaders. St. Joseph: ASABE Standards, 2006. p. 215-217.

BAIO, F.H. R.; MOLIN, J. P.; LEAL, A. J. F. Avaliação comparativa da distribuição transversal de adubos sólidos aplicados em cobertura em culturas anuais instaladas. Bioscience Journal, Uberlândia, v. 28, n. 4, p. 527-536, 2012.

BRAMLEY, R.; TRENGOVE, S. Precision agriculture in Australia: present status and recent developments. Engenharia Agrícola, Jaboticabal, v. 33, n. 3, p. 575-585, 2013.

CROZIER, C.; ROBERSON, G. T. Granular fertilizer spreader swath uniformity achieved at varying target application rates. Crop Management, Madison, v. 13, n. 1, p. 1-10, 2014.

DELAFOSSE, R. M.; BOGLIANI, M. P. Fertilizadoras centrífugas, la importancia de una correcta elección, uso y mantenimiento. Santiago: Oficina Regional de la FAO para América Latina el Caribe, 1989. 32 p.

GOSS, G. R.; BERNAL, Y.; JOHNSONBAUGH, A.; HENDERSON, R. Granular formulations and active ingredient distribution from a rotary spreader. Jai, Chicago, v. 7, n. 7, p. 35-42, 2010.

LAGHARI, M.; LAGHARI, N.; SHAH, A. R.; CHANDIO, F. A. Calibration and performance of tractor mounted rotary fertilizer spreader. International Journal of Advanced Research, New York, v. 2, n. 4, p. 839-846, 2014.

LUZ, P. H. D. C.; OTTO, R.; VITTI, G. C.; QUINTINO, T. A.; ALTRAN, W. S.; IKEDA, R. Otimização da aplicação de corretivos agrícolas e fertilizantes. Informações Agronômicas, Piracicaba, n. 129, p. 1-13, 2010.

MILAN, M.; GARDANHA JUNIOR, C. D. Ensaio e certificação das máquinas para aplicação de adubos e corretivos. In: MIALHE, L. G. Máquinas agrícolas: ensaios \& certificações. Piracicaba: Fundação de Estudos Agrários "Luiz de Queiroz", 1996. p. 515-550.

MOLIN, J. P. Adulanço 3.0: montagem do teste de campo, Manual de uso passo-a-passo, Análise de resultados. Piracicaba: USP/ESALQ, 2009. 20 p.

MOLIN, J. P.; MOTOMIYA, A. V. A.; FRASSON, F. R.; FAULIN, G. D. C.; TOSTA, W. Test procedure for variable rate fertilizer on coffee. Acta Scientiarum. Agronomy, Maringá, v. 32, n. 4, p. 569-575, 2010.

MOLIN, J. P.; MACHADO, T. M.; MAGALHÃES, R. P.; FAULIN, G. D. C. Segregação de fertilizantes aplicados a lanço. Engenharia Agrícola, Jaboticabal, v. 29, n. 4, p. 614-622, 2009. 
PARISH, R. L. Effect of rough operating surface on rotary spreader distribution pattern. Applied Engineering in Agriculture, St. Joseph, v. 7, n. 1, p. 61-63, 1991.

PORTELA, J. A.; BATISTA, D. G. Teste eletrônico. Cultivar Máquinas, Não Me Toque, n. 118, p.12-14, 2012.

SERRANO, J. M., PECA, M. J. O., SILVA, J. R.; SERRAZINA, H.; MENDES, J. Avaliação de um distribuidor centrífugo de adubo na perspectiva de utilização em agricultura de precisão.

Revista de Ciências Agrárias, Lisboa, v. 30, n. 1, p.79-86, 2007.

YILDIRIM, Y.; KARA, M. Effect of different vane combinations on fertilizer distribution uniformity with various flow rates in spinning disc broadcasters. Journal of Agricultural Sciences, Kabul, v. 18, n. 1, p. 54-62, 2012. 